\title{
Investment Decisions of the Blockchain-Based Anti- Counterfeiting Traceability Service in A High-Quality Fresh Supply Chain
}

Pan Liu ( $\sim$ hnycliupan@163.com )

Henan Agricultural University

\section{Research Article}

Keywords: Blockchain, anti-counterfeiting traceability, fresh supply chain, investment decision, coordination

Posted Date: November 8th, 2021

DOl: https://doi.org/10.21203/rs.3.rs-863623/v1

License: (c) (i) This work is licensed under a Creative Commons Attribution 4.0 International License.

Read Full License 
Investment Decisions of the Blockchain-Based Anti-Counterfeiting Traceability Service in A High-Quality Fresh Supply Chain

Pan $\mathrm{Liu}^{1 *}$

1. Information \& Management College, Henan Agricultural University, Zhengzhou, Henan, China; * Correspondence: hnycliupan@163.com

Abstract: Applications of the blockchain-based anti-counterfeiting traceability system (hereafter, blockchain-based ACTS) present a positive result in helping improve the repeat purchase rate and the product circulation rate. However, using the blockchain-based ACTS needs chain members' additional expenditure. They want to know investment conditions about the blockchainbased ACTS and how to coordinate the supply chain. To solve these problems, we chosen a supply chain with one fresh producer and one retailer as the study object. Afterwards, considering the changes of the repeat purchase rate and the product circulation rate, we revised the demand function. Then, we constructed the profit functions before and after adopting the blockchain-based ACTS, and then a price discount and revenue-sharing contract was put forward to coordinate the supply chain. Findings: with the growth of the repurchase rate, benefits of chain members in the proposed three situations will increase. Thus, we can know that after using the blockchain-based ACTS.

Keywords: Blockchain; anti-counterfeiting traceability; fresh supply chain; investment decision; coordination

\section{Introduction}

With the rapid development of Chinese economy, consumers' consumption level is improving and consumers' demand for high-quality fresh products is gradually increasing (Bumbudsanpharoke $\&$ Ko, 2015). However, the double loss phenomenon of high-quality fresh products and a series of foodstuff security incidents seriously dampened consumers' confidence in high-quality fresh products (Costa et al., 2013; Madichie \& Yamoah, 2017; LIU, 2020). Consumers are embarrassed and hesitant in choosing and purchasing the high-quality products with a high-quality price. To solve this phenomenon, many producers start to research and develop the anti-counterfeiting traceability technology. In the traditional environment, the anti-counterfeiting traceability system (based on the Internet of Things, radio frequency identification, barcode recognition, and so on) has played a very good role in solving information asymmetry and accelerating product circulation. However, in the traditional environment, the anti-counterfeiting traceability system uses a centralized data storage model. At the same time, the account book of the traditional traceability system is stored by the stakeholders of supply chain. When the account book information is unfavorable to the stakeholders, there is a tampering risk for the account book.

Therefore, to meet consumer demand for the high-quality fresh products" safety, the information transparency and the inquiry convenience, the stakeholders need a real, reliable and credible mechanism to provide a strong basis for their purchased goods. Moreover, to ensure the 
accuracy of market feedback data and preventing some sellers from fleeing goods, producers need a reliable and credible traceability system. Blockchain as a shared database has the natures of unforgeable, all traces, traceable, open and transparent. The blockchain-based anti-counterfeiting traceability system (hereafter, blockchain-based ACTS) can effectively improve the data credibility and the trust between organizations (Sunny et al., 2020), and then solve the aforementioned problems. Meanwhile, it can reinforce consumers' confidence in food goods (Papa, 2017).

Therefore, some fresh producers and retailers begin to use the blockchain-based ACTS, Such as, HeiLongJiang Agriculture Company Limited (producer), Walmart (retailer) and Tyson Food (Galvin, 2017; Taste, 2020). In addition, its applications in JD Zhizhen chain and Alibaba ant chain have proved that it can help to improve the repeat purchase rate and the product circulation rate (Digital, 2020). However, for many fresh producers and retailers, using the blockchain-based ACTS needs the additional expenditure. Therefore, they want to know the investment conditions about the blockchain-based ACTS and how to coordinate the supply chain after adopting the blockchainbased ACTS.

Although, some efforts have been done to analyze the applications of blockchain technology in product traceability, most of these researches focused on challenges, opportunities, and the fusion applications of blockchain and other technologies,. Meanwhile, they ignored the game relationships between product operators. Then, in a fresh supply chain, discussing the investment issues about the blockchain-based ACTS and coordination rules is few considering the changes of the repeat purchase rate and the product circulation rate. Therefore, in this study, we will explore the above problems.

Our aims are to gain the investment thresholds of the blockchain-based ACTS in different investments situations and the suitable contract to coordinate the supply chain after using the blockchain-based ACTS. To finish the aforementioned goals, we chosen a supply chain with one fresh producer and one retailer as the study object. Afterwards, considering the changes of the repeat purchase rate and the product circulation rate in the new technology environment, we revised the demand function. Then, based on the Stackelberg game and considering the repeat purchase rate and the product circulation rate, we constructed the profits functions before and after adopting the blockchain-based ACTS. Then a price discount and revenue-sharing contract was put forward to coordinate the supply chain after adopting the blockchain-based ACTS. Finally, we analyzed the investment thresholds of the blockchain-based ACTS in different investments situations and the coordination conditions.

The main innovations: 1) considering the changes of the repeat purchase rate and the product circulation rate in the new background, we refactored the demand function model. 2) We built four benefits models considering the blockchain-based ACTS costs and the changes of the repeat purchase rate and the product circulation rate. 3) We proposed a price discount and revenue-sharing contract to coordinate the supply chain. 
This research has some values. 1) The proposed demand function model will enrich the demand function research in the new environment and can provide a theoretical support for retailers and fresh producers to forecast market demand. 2) The proposed investment condition about the blockchain-based ACTS will enrich the investment decision theory of the fresh supply chain and can help fresh producers and retailers to make a decision when they want to invest in the blockchainbased ACTS. 3) The proposed price discount and revenue-sharing contract will enrich the coordination theory of fresh supply chain and will be a strong support for coordinating the supply chain after adopting the blockchain-based ACTS.

We organize this study as follows figure 1

\section{.2 Literature review}

The term blockchain appeared in 2008 (Nakamoto, 2008). Following its advantages in tamper proof, distribution, transparency and security, in the traceability area of agricultural products, its application was widely approbated. Previous researches related to our study are mainly concentrated in 1) the applications of the blockchain-based traceability system in a fresh supply chain, 2) investment decision and coordination of fresh supply chain considering the blockchain-based ACTS inputs.

\subsection{Appliances of the blockchain-based traceability system in fresh supply chain}

Discussions about the blockchain-based traceability system main concentrate on technical aspects, adoption factors, and so on. Effects of the appliances of the blockchain-based traceability system on chain members' decision strategies are few concerned.

Researches about the blockchain-based traceability main focused on technical aspects, for instance, some researches combined blockchain and RFID (NFC) to design a traceability system (Boehm, Kim, \& Hong, 2017). However, this system cannot solve the expandability problem about blockchain. Therefore, Salah et al. (2019) put forward a new traceability framework based on Ethereum blockchain and smart contracts for in a soybean supply chain. To improve food safety,Tian (2016) described the BigchainDB system. And based on IOT, Blockchain and Hazard Analysis and Critical Control Points (HACCP), he/she developed a new traceability system for agri-food/fresh supply chain. Similar with Tian's (2016) research, Rejeb (2018) also discussed the blockchainbased traceability system based on IOT, Blockchain and HACCP. These blockchain-based traceability systems can solve the deficiencies of the centralized traceability system, however, these system exist 


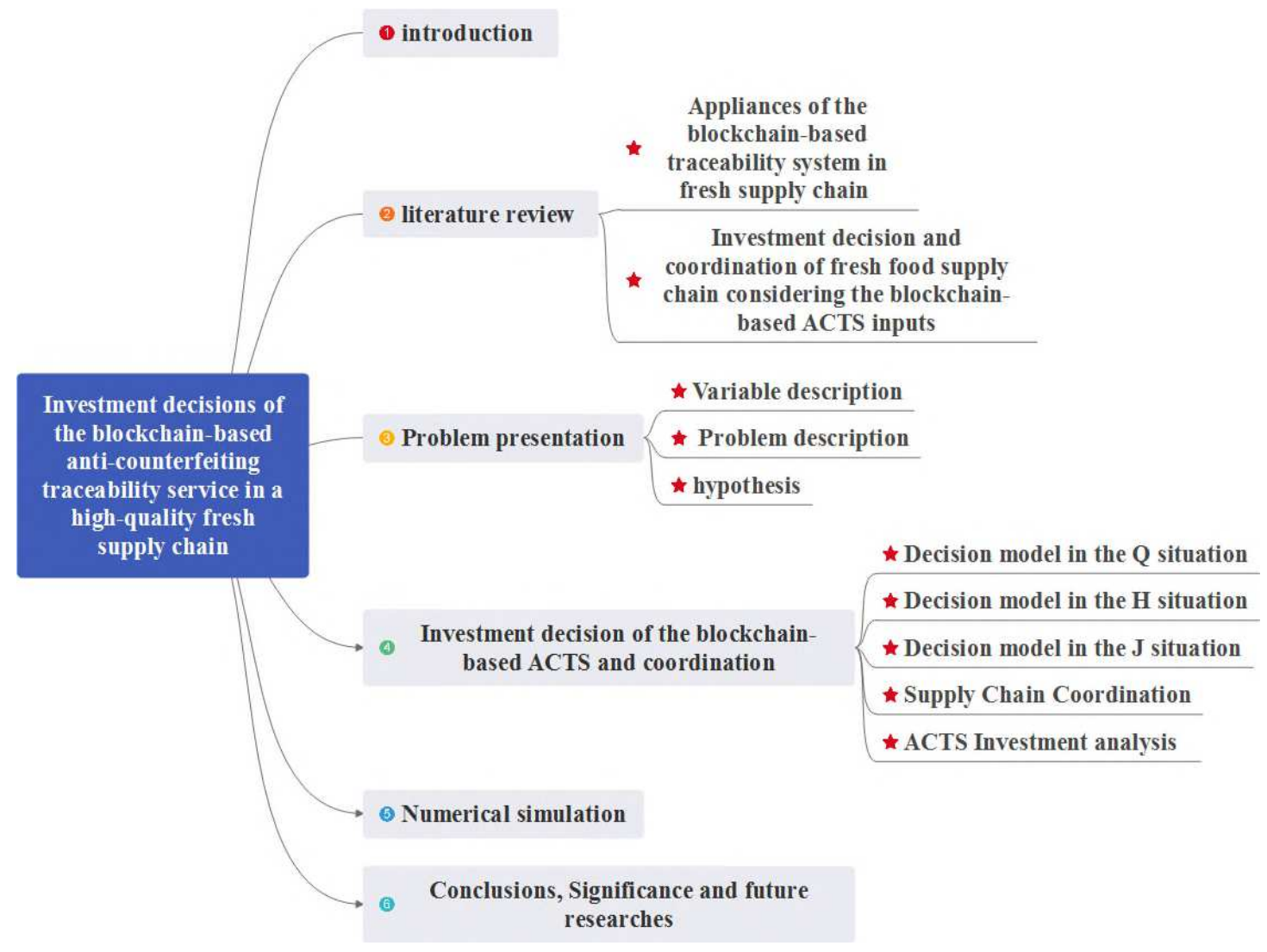

Figure 1. Research frame

some storage issues. Thus, Tsang et al. (2019) added fuzzy logic method in the traceability system composed of blockchain and IOT. To resolve the storage problems of the blockchain-based system, cloud technology and storage rules were discussed (Sambrekar et al., 2019; He et al., 2019). However, most of these systems couldn't meet the demands of management and traceability in an agri-food/fresh supply chain, and then Chen et al. (2021) proposed a blockchain-based traceability framework and used a deep reinforcement learning method to meet the demands of management and traceability in an agri-food/fresh supply chain.

In addition, there are some documents to assess the application challenges of the blockchainbased system in a food supply chain (Zhao, Liu, \& Lopez, 2019; Khler \& Pizzol (2020). Some documents focused on the adoption behaviors of blockchain technology in a food supply chain. Such as, S. Kamble (2019) and Ssk et al. (2020) used technology acceptance model to do analyses. Based on a new method called TISM and MICMAC analysis, Tayal et al. (2020) obtained the key success factors of food supply chain by using blockchain (including transparency, fraud, etc.). However, according to a wine supply chain, Ss \& Kd (2020) found that the important factors influencing blockchain adoption were dis-intermediation, traceability, and so on. Kamble, Gunasekaran, \& Sharma (2019) also proved that the traceability was the important factors for a food supply chain to use blockchain. In addition, there are other efforts to do this work, such as Kristoffer \& David (2018), Kamble et al. (2020), etc. 
In fact, some practical application cases are also explored. Such as, the Bumble Bee Foods adopted the blockchain-based traceability system to track fresh fish. Consumers could gain the fish's information from ocean to table (News, 2019). Maersk as a logistics service provider also adopted blockchain to help its chain members to track products (Sohu, 2018). JD as a large e-commerce retailer from China not only developed and used the blockchain-based traceability system for its self-operated goods, but also provided the blockchain-based ACTS for other retailers and producers in their platform. A report about the blockchain-based ACTS application survey from JD showed that comparing with the traditional traceability system, the blockchain-based traceability system could help to improve the repeat purchase rate and the product circulation rate (Digital, 2020). A survey about Alibaba ant chain also gained similar results.

Based on the above discussions, we can easily gain that 1) Purchasing the blockchain-based ACTS from other providers is a common way for chain members. Discussing its investment decision rules is important, however, this research is few. 2) The applications of the blockchain-based traceability system can help users to improve the repeat purchase rate and the product circulation rate. However, focusing on the two changes to discuss chain members' investment strategy about the blockchain-based ACTS is shortage.

2.2 Investment decision and coordination of fresh food supply chain considering the

\section{blockchain-based ACTS inputs}

Our job is also related to the investment decision and coordination of a fresh food supply chain in the traditional environment and the blockchain environment.

In the traditional environment, based on game theory, efforts about the effects of the product traceability on operating decisions of fresh supply chain are relatively abundant. For instance, Pouliot (2008) thought that traceability had an important impact on the market demand. Considering the relationships between traceability and product recall, some researches discussed benefits and coordination strategies of a fresh supply chain (Piramuthu, Farahani, \& Grunow, 2013; Dai et al., 2021). Saak \& Alexander (2013) discussed why and when decision makers to invest in a traceability system, and whether they should salve product origin information or not. If there is no proper management mechanism, the adoption of traceable product labelling system may not achieve the desired effects (Sy \& Kz, 2020). In addition, Aiello, Enea, \& Muriana (2015) evaluated the expected value and profits after implementing an RFID-based traceability system in a fresh supply chain. Dai, Tseng, \& Zipkin (2015) proposed a revenue-sharing contract to coordinate the supply chain after using the traceability system. They thought that the strict tracking regulation would be more effective than subsidies in improving supply chain tracking ability (Dai, Fan, Lee, \& Li, 2017). Some researches thought product traceability could improve the double loss of high-quality fresh products (Cai et al., 2010; Cai et al., 2013).

In the blockchain environment, based on game theory, the research achievements are shortage. Some related researches are as follows. Pedersen, Risius, \& Beck (2019) proposed a ten-step 
decision method to decide when to adopt blockchain for an organization. Considering a supply chain with one producer and one retailer, Hayrutdinov, Saeed, \& Rajapov (2020) studied decision makers' investment decision problems considering the lifecycle information sharing effort, and then a costsharing contract, a revenue-sharing contract and a cost and revenue-sharing contract were put forward to coordinate supply chain. They thought that the cost and revenue sharing contract can help chain members gain more benefits. In addition, Based on a three-stage supply chain with one retailer, one supplier and one manufacturer, Fan, Wu, \& Cao (2020) discussed decision makers' investment decision problems about blockchain considering consumers' traceability awareness and the costs using blockchain technology, and then used a revenue-sharing contract to coordinate supply chain. However, they do not focus on a fresh supply chain. Almost at the same time, focusing on a fresh supply chain and considering the changes of consumers in product safety and quality before and after adopting blockchain, LIU (2020) discussed decision makers' investment decision issues about the information service based on blockchain and big data, and then adopted a costsharing and revenue-sharing contract to achieve supply chain coordination. In the blockchain environment, based on a three-stage supply chain with one high-quality fresh products supplier, one e-retailer and one logistics provider, Wu, Fan, \& Cao (2021) discussed the pricing rules considering the consumer preference degree to the traceability information and the traceability cost, and then a two-part tariff contract was proposed to coordinate supply chain. They thought that using the blockchain-based traceability system is not always the best choose for decision makers.

Based on the above discussions, we can easily gain that 1) applications of product traceability would help chain members reduce fresh loss by improving the product circulation rate, however, previous researches overlooked these in the blockchain environment. 2) Although some investigators discussed the investment decision of the blockchain-based system, the investment model was researched and developed by supply chain members themselves and overlooked the purchase situation of ACTS. 3) Based on game theory, previous efforts did not consider the repeat purchase rate and the product circulation rate to discuss the investment rules of a fresh supply chain about ACTS. 4) In addition, previous efforts did not use a price discount and revenue-sharing contract to achieve the supply chain used the blockchain-based ACTS coordination.

Thus, in our paper, considering the changes of the repeat purchase rate and the product circulation rate after adopting the blockchain-based ACTS, we will proposed four investment situation, and then discuss the investment conditions of chain members in different investment situations. Finally, we will use a price discount and revenue-sharing contract to achieve the supply chain coordination after using the lockchain-based ACTS.

\section{Variables and Problem descriptions}

\subsection{Variable description}

The involved parameters of our research are shown in Table 1. 
Table 1

Variable description

\begin{tabular}{|c|c|}
\hline Variable & Explanation \\
\hline$a$ & Potential market demand. \\
\hline$i$ & $\begin{array}{l}\text { The different investment situation about the blockchain-based ACTS. } i=\{Q, H, J, C\} . \text { The } Q \\
\text { situation expresses that decision makers in the fresh food supply chain will not invest in ACTS. The } \\
H \text { situation expresses that decision makers in the fresh food supply chain will invest in ACTS. The } \\
J \text { situation stands for the centralized model when chain members have invested in ACTS. The } C \\
\text { situation shows the contract coordination model. }\end{array}$ \\
\hline & The proportion of the actual potential market demand. Here, $0 \leq t \leq 1$. \\
\hline$e$ & The price-sensitive coefficient of the market demand. \\
\hline$\varphi(t)$ & The effective output factor function. \\
\hline$\theta(t)$ & The decay function of freshness. \\
\hline$t^{i}$ & The product circulation time in the $i$ situation and $0 \leq t \leq T$. \\
\hline$T$ & The product lifecycle. \\
\hline$c_{p}$ & The unit production cost of high-quality fresh products. \\
\hline$c_{s}$ & The unit circulation cost of high-quality fresh products. \\
\hline$c_{o w}$ & The unit cost of the blockchain-based ACTS from the producer. \\
\hline$c_{o r}$ & The unit cost of the blockchain-based ACTS from the retailer. \\
\hline$\pi_{r}^{i}$ & Revenues of the retailer in the $i$ situation. \\
\hline$\pi_{w}^{i}$ & Benefits of the high-quality fresh products producer in the $i$ situation. \\
\hline$\gamma^{i}$ & The repeat purchase rate in the $i$ situation, here, $1 \geq \gamma^{i} \geq 0$ \\
\hline$D^{i}$ & The actual market demand in the $i$ situation, in this paper, it equals to the retailer's order quantity. \\
\hline$p^{i}$ & The retail price of the high-quality fresh products in the $i$ situation. \\
\hline$w^{i}$ & The wholesale price of the high-quality fresh products in the $i$ situation. \\
\hline$r$ & The retailer's revenue-sharing coefficient. \\
\hline
\end{tabular}

\subsection{Problem description}

\subsubsection{Supply chain structure}

In China, the producer of fresh produce comes in many forms. To simplify our research model, we chosen a supply chain with a producer (such as, agricultural cooperative, production base, and leading enterprises), a retailer and consumers as the research object. The supply chain model see figure 2 .

In figure 2, to increase consumers' confidence to the product quality, the producer and the retailer may use the blockchian-based ACTS. Generally, some information service company will 
provide the blockchain-based ACTS (such as, IBM, Baidu, and so on). Certainly, some retailers who have the ability to research and develop the blockchain technology will also provide the blockchainbased ACTS, such as, JD's Zhizhen chain and Alibaba's ant chain, both of them is from china. In this paper, we assume that the producer and the retailer will buy the blockchain-based ACTS from an information service provider. The retailer provides inventory and other information that can prove the authenticity of the product. The producer offers product production information distribution information, quality certification information and other information that can verify the authenticity of the product. Meanwhile, the producer and the retailer will require its logistics service providers to upload product logistics information. Through the platform of the blockchian-based ACTS, consumers can look at these information.

When all members of the supply chain use the blockchain-based ACTS, the traceability can achieve the best effect. In fact, the core enterprises are also trying their best to promote this state. Thus, we assume that there are four investment situations for chain members. 1) Decision makers in the fresh food supply chain will not invest in ACTS (The $Q$ situation). 2) Decision makers in the fresh food supply chain will invest in ACTS (The $H$ situation). 3) The centralized model when chain members have invested in ACTS (The $J$ situation). 4) The contract coordination model after decision makers adopting the blockchain-based ACTS (The $C$ situation).

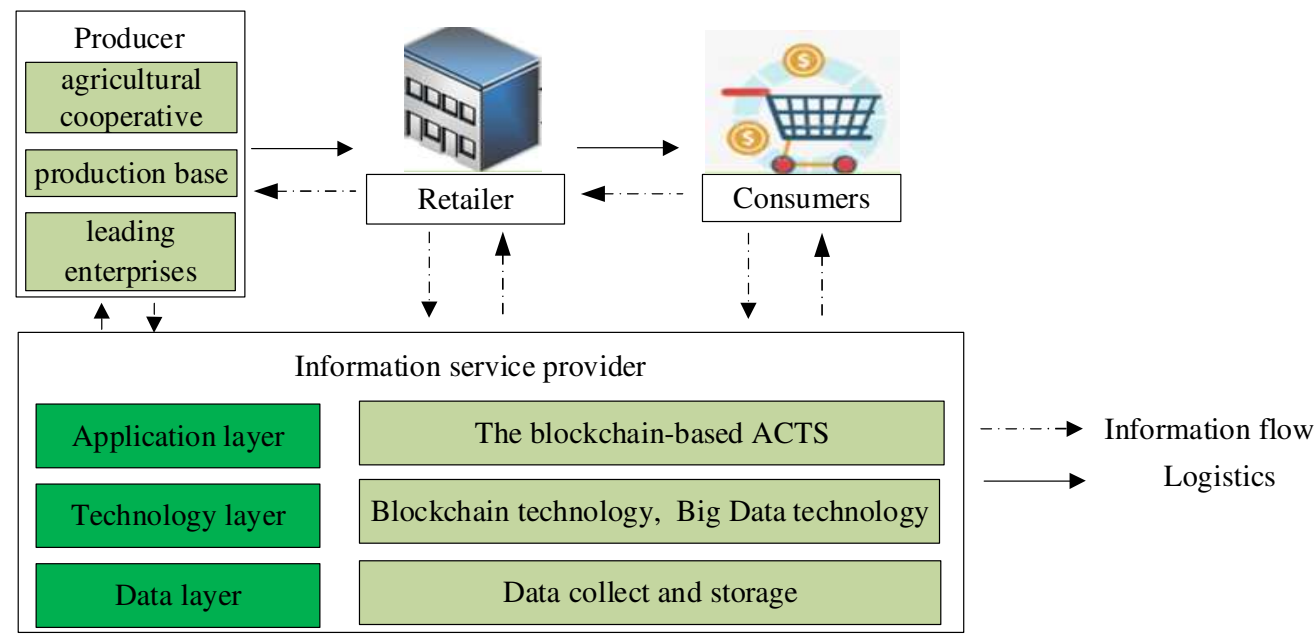

Figure. 2 The supply chain structure after adopting the blockchain-based ACTS

In this paper, we only focus on the investment decisions of the producer and the retailer about the blockchain-based ACTS. Therefore, we further simplify the supply chain model and get figure 3. Due to agricultural cooperative, production base and leading enterprises belong to the attributes of the producer, thus, we see them as producer. 


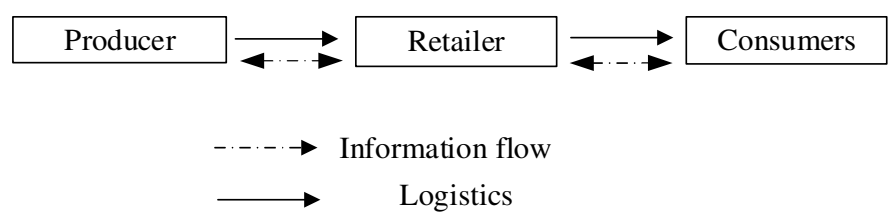

Figure. 3 The simplified supply chain model

\subsubsection{Decision process}

Usually, the producer and the retailer will implement a decision with maximizing their own interests, and the competition between the producer and the retailer conforms to master-salve game. Before using the blockchain-based ACTS, the producer as the game leader will offer the high-quality fresh products with the lifecycle $T$ and consider the circulation loss and costs to set a wholesale price $w^{Q}$. Then, the retailer as the game follower will set the order quantity $D^{Q}$ based on the wholesale price $w^{Q}$. The producer will decision the shipments $D^{Q} j \quad\left(t^{Q}\right)$ considering the retailer's order quantity and the circulation loss. When the retailer receives the high-quality fresh products, it will set the retail price $p^{Q}$ according to the market reaction and product freshness $q\left(t^{Q}\right)$.

After using the blockchain-based ACTS, if it is in the $\mathrm{H}$ situation, firstly, the producer will offer the high-quality fresh products with the lifecycle $T$. Meanwhile, the producer will consider the new circulation loss and the possible promote amplitude in market demand to decide the investment costs of the blockchain-based ACTS $c_{o w}$, and then according to the new costs to set a wholesale price $w^{H}$. Then, the retailer as the game follower will decide the order quantity $D^{H}$ according to the wholesale price $w^{H}$. The producer will decide the shipments $D^{H} / j\left(t^{H}\right)$ considering the retailer's order quantity and the circulation loss. When the retailer receives the highquality fresh products, it will set the retail price $p^{Q}$ according to the market reaction, product freshness $q\left(t^{Q}\right)$ and the investment costs of the blcokchain-based ACTS $c_{o r}$.

After using the blockchain-based ACTS, if it is in the $\mathrm{J}$ situation, supply chain members will decide the related decision variables together. Firstly, the retailer and the producer will set the retail price $p^{J}$ according to the possible market demand $D^{J}$, and then based on $D^{J}$ and the new circulation loss, they will decide the shipments $D^{J} f j\left(t^{J}\right)$. Moreover, they will set the investment costs of the blockchain-based ACTS $c_{o w}$ and $c_{o r}$ according to the possible promote amplitude in market demand.

After using the blockchain-based ACTS, if it is in the C situation, firstly, the producer will offer the high-quality fresh products with the lifecycle $T$. To encourage the retailer to order more products and use the blockchain-based ACTS, the producer may set a low wholesale price $w^{c}$. Meanwhile, the retailer will return a certain percentage of revenues to the producer. Therefore, in this situation, the producer consider the new circulation loss and the possible promote amplitude in the market demand to decide the investment costs of the blockchain-based ACTS $c_{\text {ow }}$. And then 
according to the new costs and to encourage the retailer, the producer sets a wholesale price $w^{c}$. Then, the retailer as the game follower will decide the order quantity $D^{c}$ and the returned income percentage $r$ based the wholesale price $w^{c}$. The producer will decide the shipments $D^{c} / j\left(t^{c}\right)$ considering the retailer's order quantity and the circulation loss. When the retailer receives the highquality fresh products, it will set the retail price $p^{c}$ according to the market reaction, product freshness $q\left(t^{C}\right)$ and the investment costs of the blcokchain-based ACTS $c_{o r}$.

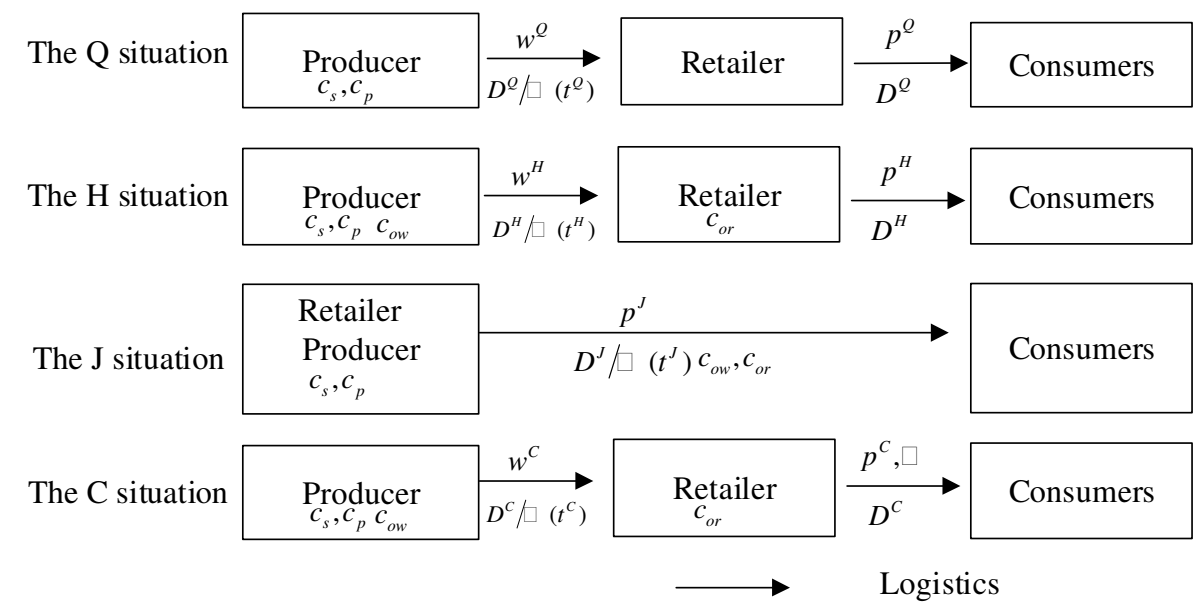

Figure 4. Game process in the proposed four situations

\subsubsection{Demand function}

The high-quality fresh products as a special product is different from industrial products. Product freshness is an important factor and will affect the market demand. The authenticity of highquality fresh products also will affect demand. Based on a report from JD blockchain Open Platform, we know that the blockchain-based ACTS can help producers and retailers add the repeat purchase rate and sales volume (Digital, 2020). Meanwhile, the blockchain-based ACTS can add the product circulation rate. Meanwhile, the market demand is price-sensitive. Combined the researches of Cai et al. (2010) and Wen-Li \& Zhao (2019a), we revised the market demand function after adopting the blockchain-based ACTS.

$$
D^{i}=\left(1+\gamma^{i}\right)\left(\tau^{x} a-e p^{i}\right) \theta\left(t^{i}\right)
$$

In the formula (1), due to applications of the blockchain-based ACTS can add the market demand by adding consumers trust to product (Digital, 2020; Fan, Wu, \& Cao, 2020; Wu, Fan, \& Cao, 2021). Thus, when $i=Q, x=1$, otherwise, $x=0$. After adopting the blockchain-based ACTS, the circulation speed of the high-quality fresh products will add and the circulation time will reduce. Then, the double loss of the high-quality fresh products will decrease. Thus, before and after using the blockchain-based ACTS, the circulation time $t^{Q}>t^{H}$. Assume that $t^{C}=t^{H}=t^{J}$. Then, we can get $q\left(t^{C}\right)=q\left(t^{H}\right)=q\left(t^{J}\right)>q\left(t^{Q}\right)$, and $i \quad\left(t^{C}\right)=j\left(t^{H}\right)=j\left(t^{J}\right)>j\left(t^{Q}\right)$. Without loss of generality, 
$0 \leq c_{p}+c_{s} \leq w^{i} \leq p^{i}$

\section{3 hypothesis}

(1) Producers and retailers are two types of independent groups, both of them is risk-neutral and completely rational, and their decision-making principles are to maximize their own interests. Both parties have the same information. The retailer and the consumers are in the same city or region, meanwhile, the producer has enough production capacity.

(2) Consumers are like the high-quality fresh products. In other words, they will pay more for the high-quality fresh products with high freshness and low price.

(3) Because high-quality fresh products are fragile and easily damaged, inevitably, they will be lost during the circulation process. The longer the transportation time, the more the loss quantity. If it reaches the lifecycle time T, it will be all wasted. Namely, $i \quad(1)=1 j \quad(T)=0$. To ensure the valid product quantity after arriving at the retailer, the shipments of the producer is $D^{i} j j\left(t^{i}\right)$.

\section{Investment decision of the blockchain-based ACTS and coordination}

Aims of our research are to gain the investment threshold of ACTS and design a contract to coordinate the supply chain. To achieve our goal, we put forward four investment situations and the research idea see Figure 5. Firstly, we will build the benefit models in the situations of Q and H, and then through comparing the revenues of the two situations we can gain the investment threshold. Afterwards, we will construct the revenue model of the $\mathrm{J}$ situation, and then through comparing the revenues of the situations of $\mathrm{J}$ and $\mathrm{H}$ we can know whether the revenues of chain members in the $\mathrm{H}$ situation is the best. If it is not, we will propose a contract to coordinate the supply chain.

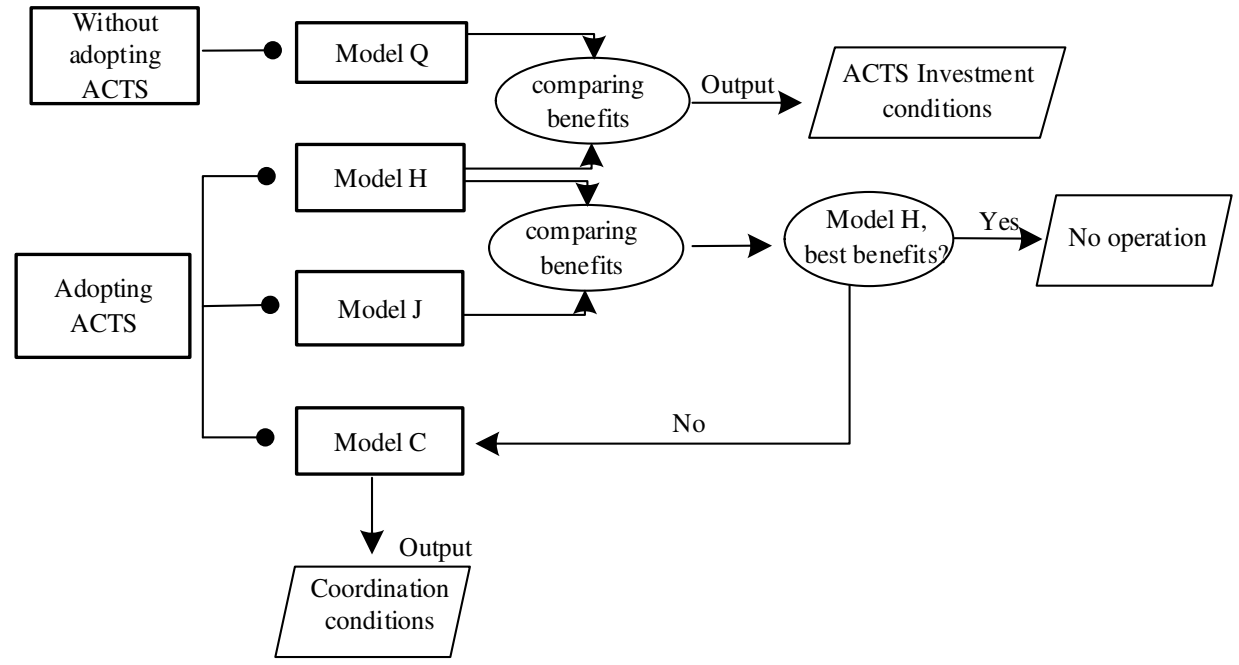

Figure 5 Research idea map

\subsection{Decision model in the $Q$ situation}

When the high-quality fresh products producer and the retailer haven't adopted ACTS, 
consumers have no way to verify the authenticity of the high-quality fresh products. Therefore, in the first period of sale, the potential market demand $a$ will drop to : $a$, and at the same time, this also has a negative influence on the repurchase rate and the product circulation rate will be lower than it in other situations. Therefore, revenues of the producer and the retailer can be expressed as functions (3) and (4), respectively.

$$
\begin{aligned}
& \pi_{w}^{Q}=w^{Q}\left(1+\gamma^{Q}\right)\left(\tau a-e p^{Q}\right) \theta\left(t^{Q}\right)-\left(c_{p}+c_{s}\right)\left(1+\gamma^{Q}\right)\left(\tau a-e p^{Q}\right) \theta\left(t^{Q}\right) / \varphi\left(t^{Q}\right) \\
& \pi_{r}^{Q}=\left(p^{Q}-w^{Q}\right)\left(1+\gamma^{Q}\right)\left(\tau a-e p^{Q}\right) \theta\left(t^{Q}\right)
\end{aligned}
$$

Because the producer occupies a dominant position, the fresh food supply conforms to the master-slave game. Firstly, the producer set the wholesale price based on market sensitivity and shipments. Then, the retailer set the retail price based on the market sensitivity and the wholesale price. Due to the insufficient of the effective supply about the high-quality fresh products, there is no surplus of the supplied commodities. Therefore, using the reverse order solution method and according to functions (2) and (4), we obtained the optimal retail price and the optimal wholesale price.

$$
\begin{gathered}
p^{Q^{*}}=\frac{e c_{p}+e c_{s}+3 \tau a \varphi\left(t^{Q}\right)}{4 e \varphi\left(t^{Q}\right)} \\
w^{Q^{*}}=\frac{e c_{p}+e c_{s}+\tau a \varphi\left(t^{Q}\right)}{2 e \varphi\left(t^{Q}\right)}
\end{gathered}
$$

Putting $p^{Q^{*}}$ and $w^{Q^{*}}$ into functions (5) and (6), we can obtain functions (7) and (8). Meanwhile, the optimal sales volume $D^{Q^{*}}$ can be got.

$$
\begin{aligned}
& \pi_{w}^{Q^{*}}=\frac{\theta\left(t^{Q}\right)\left(1+\gamma^{Q}\right)\left[\tau a \varphi\left(t^{Q}\right)-e c_{p}-e c_{s}\right]^{2}}{8 e \varphi\left(t^{Q}\right)^{2}} \\
& \pi_{r}^{Q^{*}}=\frac{\theta\left(t^{Q}\right)\left(1+\gamma^{Q}\right)\left[\tau a \varphi\left(t^{Q}\right)-e c_{p}-e c_{s}\right]^{2}}{16 e \varphi\left(t^{Q}\right)^{2}} \\
& D^{Q^{*}}=\frac{\theta\left(t^{Q}\right)\left(1+\gamma^{Q}\right)\left[\tau a \theta\left(t^{Q}\right)-e c_{p}-e c_{s}\right]}{4 \varphi\left(t^{Q}\right)}
\end{aligned}
$$

Without loss of generality, $D^{Q^{*}}$ should be greater than 0 , thus, we get $\tau a \theta\left(t^{Q}\right)>e c_{p}+e c_{s}$.

Meanwhile, when $\tau a \theta\left(t^{Q}\right)>e c_{p}+e c_{s}, \quad p^{Q^{*}} \geq w^{Q^{*}} \geq 0$.

\subsection{Decision model in the $H$ situation}

When the high-quality fresh products producer and the retailer have adopted ACTS, consumers can verify the authenticity of the high-quality fresh products. Therefore, in the first period of sale, the potential market demand will be higher than it in the $\mathrm{Q}$ situation, and is $a$. Moreover, this also 
has a positive influence on the repurchase rate $g$ and the product circulation rate will be higher in this situation.

After adopting ACTS, the circulation time of high-quality fresh products will reduce and the main reasons are as follows. 1) Through automatic identification of goods and automatic data collection, the operation process can be simplified, and then reduce circulation time. 2) Consumers can quick verify the authenticity of the high-quality fresh products, and this will reduce the consumers' time in choosing the high-quality fresh products. 3) The increase of the repurchase rate will add the product circulation rate in the warehouse. The reduction of the circulation time will reduce the loss of high-quality fresh products. Therefore, $\varphi\left(t^{H}\right)>\varphi\left(t^{Q}\right)$. Revenues of the highquality fresh products producer and the retailer can be expressed as functions (10) and (11), respectively.

$$
\begin{aligned}
& \pi_{w}^{H}=w^{H}\left(1+\gamma^{H}\right)\left(a-e p^{H}\right) \theta\left(t^{H}\right)-\left(c_{p}+c_{s}+c_{o w}\right)\left(1+\gamma^{H}\right)\left(a-e p^{H}\right) \theta\left(t^{H}\right) / \varphi\left(t^{H}\right) \\
& \pi_{r}^{H}=\left(p^{H}-w^{H}-c_{o r}\right)\left(1+\gamma^{H}\right)\left(a-e p^{H}\right) \theta\left(t^{H}\right)
\end{aligned}
$$

Using the reverse order solution method and according to functions (2) and (11), we obtained the optimal retail price and the optimal wholesale price.

$$
\begin{aligned}
p^{H^{*}} & =\frac{e c_{p}+e c_{s}+3 \dot{g} \quad\left(t^{H}\right)+e c_{o w}+e c_{o} i \quad\left(t^{H}\right)}{4 \dot{g}\left(t^{H}\right)} \\
w^{H^{*}} & =\frac{e c_{p}+e c_{s}+g \quad\left(t^{H}\right)+e c_{o w}-e c_{o} i \quad\left(t^{H}\right)}{2 \dot{g}\left(t^{H}\right)}
\end{aligned}
$$

Putting $p^{H^{*}}$ and $w^{H^{*}}$ into functions (10) and (11), we can obtain functions (14) and (15). Meanwhile, the optimal sales volume $D^{H^{*}}$ can be got.

$$
\begin{aligned}
& \pi_{w}^{H^{*}}=\frac{\theta\left(t^{H}\right)\left(1+\gamma^{H}\right)\left[a \varphi\left(t^{H}\right)-e c_{p}-e c_{s}-e c_{o w}-e c_{o r} \varphi\left(t^{H}\right)\right]^{2}}{8 e \varphi\left(t^{H}\right)^{2}} \\
& \pi_{r}^{H^{*}}=\frac{\theta\left(t^{H}\right)\left(1+\gamma^{H}\right)\left[a \varphi\left(t^{H}\right)-e c_{p}-e c_{s}-e c_{o w}-e c_{o r} \varphi\left(t^{H}\right)\right]^{2}}{16 e \varphi\left(t^{H}\right)^{2}} \\
& D^{H^{*}}=\frac{\theta\left(t^{H}\right)\left(1+\gamma^{H}\right)\left[a \theta\left(t^{H}\right)-e c_{p}-e c_{s}-e c_{o w}-e c_{o r} \theta\left(t^{H}\right)\right]}{4 \varphi\left(t^{H}\right)}
\end{aligned}
$$

Without loss of generality, $D^{H^{*}}$ should be greater than 0 , thus, we get $a \theta\left(t^{H}\right)>e c_{p}+e c_{s}+e c_{o w}+e c_{o r} \theta\left(t^{H}\right)$. Meanwhile, when $a \theta\left(t^{H}\right)>e c_{p}+e c_{s}+e c_{o w}+e c_{o r} \theta\left(t^{H}\right)$, $p^{H^{*}} \geq w^{H^{*}} \geq 0$.

Based on functions (14) and (15), we can get the revenues of the total supply chain $\pi^{H^{*}}$. $\pi^{H^{*}}=\pi_{r}^{H^{*}}+\pi_{m}^{H^{*}}=\frac{3 \theta\left(t^{H}\right)\left(1+\gamma^{H}\right)\left[a \varphi\left(t^{H}\right)-e c_{p}-e c_{s}-e c_{o w}-e c_{o r} \varphi\left(t^{H}\right)\right]^{2}}{16 e \varphi\left(t^{H}\right)^{2}}$. 


\subsection{Decision model in the $\mathrm{J}$ situation}

In the centralized decision model, chain members have adopted ACTS, and to maximize their benefits, they will set the retail price together. In this situation, profits of the high-quality fresh products supply chain can be expressed as function (17).

$$
\pi^{J}=\left(p^{J}-c_{o r}\right) D^{J}-\frac{\left(c_{p}+c_{s}+c_{o w}\right) D^{J}}{\varphi\left(t^{J}\right)}
$$

Based on functions (17), we can obtain the optimal retail price $p^{J *}$. Putting $p^{J^{*}}$ into function (17), we can get the optimal revenues $\pi^{J^{*}}$ and the market demand $D^{J^{*}}$ in the $\mathrm{J}$ situation.

$$
\begin{aligned}
\pi^{J^{*}} & =\frac{\left(1+\gamma^{J}\right) \theta\left(t^{J}\right)\left[\varphi\left(t^{J}\right)-e c_{o w}-e c_{p}-e c_{s}-e c_{o r}\right]^{2}}{4 e \varphi\left(t^{J}\right)^{2}} \\
Q^{J *} & =\frac{\left(1+\gamma^{J}\right) \theta\left(t^{J}\right)\left[a \varphi\left(t^{J}\right)-e c_{o w}-e c_{p}-e c_{s}-e c_{o r} \varphi\left(t^{J}\right)\right]}{2 \varphi\left(t^{J}\right)} \\
p^{J *} & =\frac{a \varphi\left(t^{J}\right)+e c_{o w}+e c_{p}+e c_{s}+e c_{o r} \varphi\left(t^{J}\right)}{2 e \varphi\left(t^{J}\right)}
\end{aligned}
$$

Through comparing the total revenues of supply chain in the situations of $\mathrm{H}$ and $\mathrm{J}$, we can get that the total profit of supply chain in the $\mathbf{J}$ situation is higher than it in the $\mathrm{H}$ situation. Namely, after adopting ACTS, the supply chain has not achieved coordination. In the next, we will set a contract to coordinate supply chain.

\subsection{Supply Chain Coordination}

According to functions (20) and (12), we get that $p^{H^{*}}-p^{J^{*}}=$ $\left[a \varphi\left(t^{J}\right)+e c_{o w}+e c_{p}+e c_{s}+e c_{o r} \varphi\left(t^{J}\right)\right] / 2 e \varphi\left(t^{J}\right)-\left[e c_{p}+e c_{s}+3 a \varphi\left(t^{H}\right)+e c_{o w}+e c_{o r} \varphi\left(t^{H}\right)\right] / 4 e \varphi\left(t^{H}\right)=$ $\left[a \varphi\left(t^{H}\right)-e c_{p}-e c_{s}-e c_{o w}-e c_{o r} \varphi\left(t^{H}\right)\right] / 4 e \varphi\left(t^{H}\right)>0 \quad$. Furthermore, $\quad \pi^{J^{*}}-\pi^{H^{*}}=\left(1+\gamma^{J}\right) \theta\left(t^{J}\right) \times$ $\left[\varphi\left(t^{J}\right)-e c_{o w}-e c_{p}-e c_{s}-e c_{o r}\right]^{2} / 16 e \varphi\left(t^{J}\right)^{2}>0$. The above results show that in the $\mathrm{J}$ model, the optimal retail price is lower than it in the $\mathrm{H}$ model. Meanwhile, the total profit in the $\mathrm{J}$ model is higher than it in the $\mathrm{H}$ model. Therefore, after adopting ACTS, the supply chain has not achieved coordination. To achieve supply chain coordinate, we proposed a price discount and revenue-sharing contract.

In this price discount and revenue-sharing contract, revenues of the high-quality fresh products producer and the retailer can be expressed as functions (21) and (22), respectively.

$$
\begin{aligned}
& \pi_{w}^{C}=w^{C} D^{C}-\frac{\left(c_{P}+c_{o w}+c_{s}\right) D^{C}}{\varphi\left(t^{C}\right)}+\rho p^{C} D^{C} \\
& \pi_{r}^{C}=(1-\rho) p^{C} D^{C}-\left(w^{C}+c_{o r}\right) D^{C}
\end{aligned}
$$

Using the reverse order solution method and according to functions (2) and (22), we obtained 
$p^{C}\left(w^{C}\right)$. If the total benefit of supply chain in the $\mathrm{C}$ situation wants to reach the level in the $\mathrm{J}$ situation, the retail price in the $\mathrm{C}$ situation $\left(p^{C^{*}}\right)$ should equal to $p^{J^{*}}$. Then, we obtain $w^{C^{*}}=\left[c_{p}+c_{s}+c_{o w}-r\left(c_{p}+c_{s}+c_{o w}+c_{o} i\left(t^{C}\right)\right)\right]$. Based on $p^{C^{*}}$ and $w^{C^{*}}$, we can get the optimal revenues $\pi_{r}^{c^{*}}$ and $\pi_{m}^{c^{*}}$ in the $\mathrm{C}$ situation.

$$
\begin{aligned}
& \pi_{r}^{\mathrm{C}^{*}}=\frac{(1-\rho)\left(1+\gamma^{C}\right) \theta\left(t^{C}\right)\left[a \varphi\left(t^{C}\right)-e c_{o w}-e c_{p}-e c_{s}-e c_{o r} \varphi\left(t^{C}\right)\right]^{2}}{4 e \varphi\left(t^{C}\right)^{2}} \\
& \pi_{w}^{C^{*}}=\frac{\rho\left(1+\gamma^{C}\right) \theta\left(t^{C}\right)\left[a \varphi\left(t^{C}\right)-e c_{o w}-e c_{p}-e c_{s}-e c_{o r} \varphi\left(t^{C}\right)\right]^{2}}{4 e \varphi\left(t^{C}\right)^{2}}
\end{aligned}
$$

Meanwhile, we get $D^{C^{*}}=\theta\left(t^{C}\right)\left(1+\gamma^{C}\right)\left[a \varphi\left(t^{C}\right)-e c_{o w}-e c_{s}-e c_{s}-e c_{o r} \varphi\left(t^{C}\right)\right] / 2 \varphi\left(t^{C}\right)$. Without loss of generality, $D^{C *}$ should be greater than 0 , thus, we get $a \theta\left(t^{C}\right)>e c_{p}+e c_{s}+e c_{o w}+e c_{o r} \theta\left(t^{C}\right)$. When $\pi_{r}^{C^{*}}>\pi_{r}^{H^{*}}$ and $\pi_{w}^{C^{*}}>\pi_{w}^{H^{*}}$, the price discount and revenue-sharing contract will coordinate the supply chain. Based on these, we obtain conclusion 1.

Conclusion 1. When $1 / 2<\rho<\frac{3}{4}$, adopting the price discount and revenue-sharing contract achieve the high-quality fresh products supply chain coordinate.

Proof. $\quad \pi_{r}^{C^{*}}-\pi_{r}^{H^{*}}=\frac{(3-4 \rho)\left(1+\gamma^{C}\right) \theta\left(t^{C}\right)\left[a \varphi\left(t^{C}\right)-e c_{o w}-e c_{p}-e c_{s}-e c_{o r} \varphi\left(t^{C}\right)\right]^{2}}{16 e \varphi\left(t^{C}\right)^{2}} \quad, \quad$ because $\pi_{r}^{C^{*}}>\pi_{r}^{H^{*}} \quad, \quad$ we $\quad$ get $\quad \rho<\frac{3}{4} \quad . \quad$ In $\quad$ addition, $\quad \pi_{w}^{C^{*}}-\pi_{w}^{H^{*}}=$ $\frac{(2 \rho-1)\left(1+\gamma^{C}\right) \theta\left(t^{C}\right)\left[a \varphi\left(t^{C}\right)-e c_{o w}-e c_{p}-e c_{s}-e c_{o r} \varphi\left(t^{C}\right)\right]^{2}}{8 e \varphi\left(t^{C}\right)^{2}}>0$, we get $\rho>\frac{1}{2}$. Conclusion 1 was confirmed.

\subsection{ACTS Investment analysis}

In China, JD blockchain Open Platform and the Ant chain from Ant Group have confirmed the positive effects of blockchain-based ACTS on high-quality fresh products. In 2020, a report from JD blockchain Open Platform showed that blockchain-based ACTS could help producers and retailers to add the repeat purchase rate and sales volume (Digital, 2020). Meanwhile, blockchainbased ACTS can add the product circulation rate. Based on the aforementioned advantages, many brand owners and retailers want to adopt the blockchain-based ACTS. However, if chain members 
want to gain more benefits, the following condition should be met. In other words, revenues of chain members after using the blockchain-based ACTS should be more than it in the Q situation. Immediately, $\pi_{r}^{H^{*}}>\pi_{r}^{Q^{*}}$ and $\pi_{w}^{H^{*}}>\pi_{w}^{Q^{*}}$, then, we obtain conclusion 2 .

Conclusion 2. When $\zeta_{1}$ can be met, in the H situation, adopting blockchain-based ACTS is feasible. When $c_{o r} \varphi\left(t^{H}\right)+c_{o w} \leq \min \left(\zeta_{2}, \zeta_{3}\right)$ can be satisfied, in the $\mathrm{C}$ situation, adopting blockchain-based ACTS is feasible.

Proof. According to functions (7), (8), (14) and (15), we obtain $\pi_{w}^{H^{*}}-\pi_{w}^{Q^{*}}=\frac{\theta\left(t^{H}\right)\left(1+\gamma^{H}\right)\left[a \varphi\left(t^{H}\right)-e c_{p}-e c_{s}-e c_{o w}-e c_{o r} \varphi\left(t^{H}\right)\right]^{2}}{8 e \varphi\left(t^{H}\right)^{2}}-\frac{\theta\left(t^{Q}\right)\left(1+\gamma^{Q}\right)\left[\tau a \varphi\left(t^{Q}\right)-e c_{p}-e c_{s}\right]^{2}}{8 e \varphi\left(t^{Q}\right)^{2}}$,

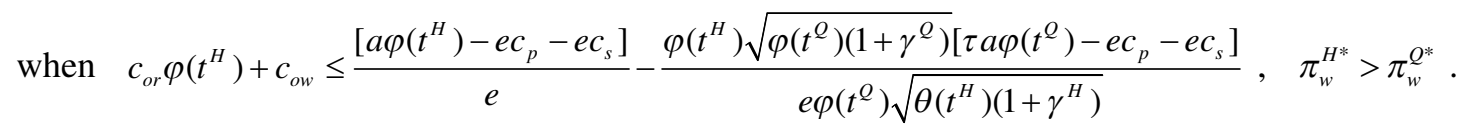
We call this condition $\quad \zeta_{1} \quad$ Moreover, $\pi_{r}^{H^{*}}-\pi_{r}^{Q^{*}}=\frac{\theta\left(t^{H}\right)\left(1+\gamma^{H}\right)\left[a \varphi\left(t^{H}\right)-e c_{p}-e c_{s}-e c_{o w}-e c_{o r} \varphi\left(t^{H}\right)\right]^{2}}{16 e \varphi\left(t^{H}\right)^{2}}-\frac{\theta\left(t^{Q}\right)\left(1+\gamma^{Q}\right)\left[\tau a \varphi\left(t^{Q}\right)-e c_{p}-e c_{s}\right]^{2}}{16 e \varphi\left(t^{Q}\right)^{2}}$,

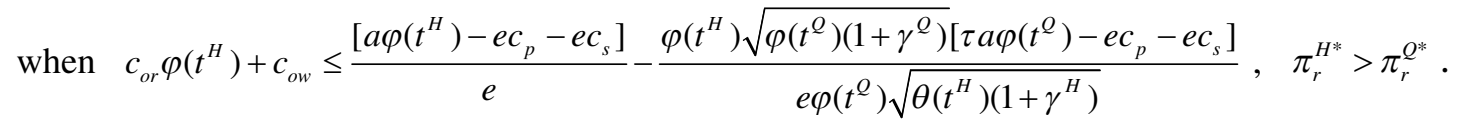

This condition is similar with condition $\zeta_{1}$.

According to functions (7), (8), (23) and (24), we obtain $\pi_{w}^{C^{*}}-\pi_{w}^{Q^{*}}=\frac{\rho\left(1+\gamma^{C}\right) \theta\left(t^{C}\right)\left[a \varphi\left(t^{C}\right)-e c_{o w}-e c_{p}-e c_{s}-e c_{o r} \varphi\left(t^{C}\right)\right]^{2}}{4 e \varphi\left(t^{C}\right)^{2}}-\frac{\theta\left(t^{Q}\right)\left(1+\gamma^{Q}\right)\left[\tau a \varphi\left(t^{Q}\right)-e c_{p}-e c_{s}\right]^{2}}{8 e \varphi\left(t^{Q}\right)^{2}}$,

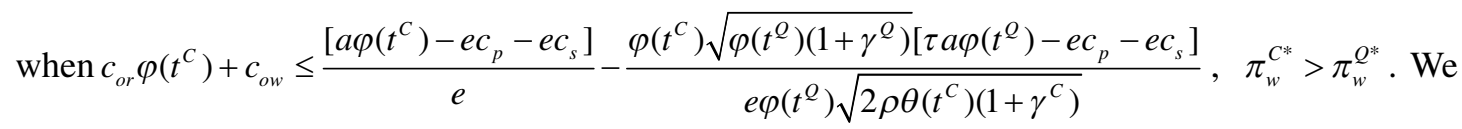
call this condition $\quad \zeta_{2} \quad$ Moreover, $\pi_{r}^{C^{*}}-\pi_{r}^{Q^{*}}=\frac{(1-\rho)\left(1+\gamma^{C}\right) \theta\left(t^{C}\right)\left[a \varphi\left(t^{C}\right)-e c_{o w}-e c_{p}-e c_{s}-e c_{o r} \varphi\left(t^{C}\right)\right]^{2}}{4 e \varphi\left(t^{C}\right)^{2}}-\frac{\theta\left(t^{Q}\right)\left(1+\gamma^{Q}\right)\left[\tau a \varphi\left(t^{Q}\right)-e c_{p}-e c_{s}\right]^{2}}{16 e \varphi\left(t^{Q}\right)^{2}}$ , when $c_{o r} \varphi\left(t^{C}\right)+c_{o w} \leq \frac{\left[a \varphi\left(t^{C}\right)-e c_{p}-e c_{s}\right]}{e}-\frac{\varphi\left(t^{C}\right) \sqrt{\varphi\left(t^{Q}\right)\left(1+\gamma^{Q}\right)}\left[\tau a \varphi\left(t^{Q}\right)-e c_{p}-e c_{s}\right]}{2 e \varphi\left(t^{Q}\right) \sqrt{(1-\rho) \theta\left(t^{C}\right)\left(1+\gamma^{C}\right)}}, \quad \pi_{r}^{C^{*}}>\pi_{r}^{Q^{*}}$.

This condition is similar with condition $\zeta_{3}$.

\section{Numerical Simulation}

To verify the effectiveness of the proposed conclusions, we will implement a numerical simulation case. Based on the research of Wen-Li \& Zhao (2019), we chose a company producing 
cherries and coming from Shandong, China. After collating information, the unit production cost of cherries $c_{p}$ is 0.8 ten thousand yuan $\mathrm{RMB} /$ ton. The shipping fee $c_{s}$ equals to 1.4 ten thousand $\mathrm{RMB} /$ ton. Assume that the market demand $a=100$ ton. The transportation time $t_{o}=4$ days. The life cycle of cherries $T=10$ days. Assume that $\varphi\left(t^{i}\right)=1-\lambda\left(t^{i}\right)=2-e_{1}^{\frac{\ln 2}{T^{i}}}$, here, $\lambda\left(t^{i}\right)=e_{1}^{\frac{\ln 2}{T^{i}}}-1 . \quad e_{1}$ is a constant and stands for the quantity loss. We set $t^{Q}=4$ and $t^{H}=t^{J}=t^{C}=3$. Based on the research of Wen-Li \& Zhao (2019), we get $\theta\left(t^{Q}\right)=1-\left(t^{i}\right)^{2} / T^{2}$. According to the report about JD blockchain Open Platform (Digital, 2020), we set $\tau=0.6, r^{Q}=0.5<r^{H}=r^{J}=r^{C}=0.8$. According to functions (7), (8), (14), (15), (23) and (24), we can get Figure 5.

In Figure 6, the abscissa represents the revenues of chain members in different situations, and the ordinate shows the repurchase rate in different situations. From Figure 5, we can get that with the growth of the repurchase rate, benefits of chain members in the proposed three situations will increase. Meanwhile, we can obtain that after adopting blockchain-based ACTS, profits of chain members will be higher than them before adopting blockchain-based ACTS. These indicates that using blockchain-based ACTS can help supply chain gain more revenues. In addition, we find that revenues of chain members in the $\mathrm{C}$ situation are more compared with them in the $\mathrm{H}$ situation. This demonstrates that the price discount and revenue-sharing contract can achieve supply chain coordinate. Thus, we can know that after using blockchain-based ACTS, if chain members want to gain more benefits, they should try their best to excavate the value of the blockchain-based ACTS and increase the repurchase rate.

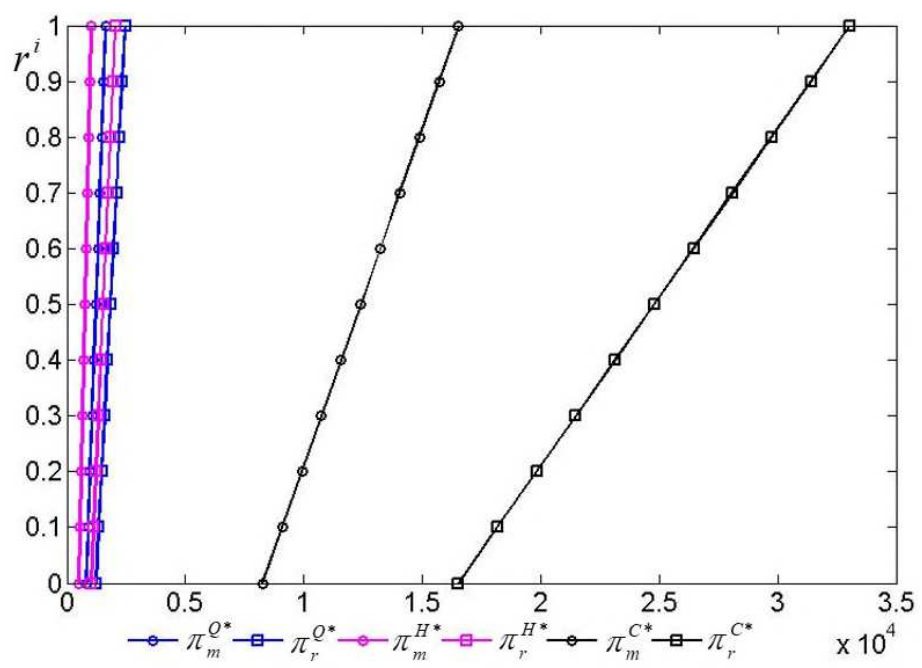

Figure 6 Relationships between chain members' revenues in different situations and the repurchase rate According to functions (7), (8), (14), (15), (23) and (24), though analyzing effects of the 
effective output factor function $\varphi(t)$ on the revenues of the producer and the retailer in the proposed three situations, we get table 1 . Based on table 1, we can understand that following the rise of the effective output factor function, profits of the producer and the retailer in different situations will reduce. However, after adopting blockchain-based ACTS, revenues of chain members are higher than them before using blockchain-based ACTS. In addition, we also find that in the C situation, the effects of the effective output factor function $\varphi(t)$ on supply chain benefits are relatively smaller compared with them in the $\mathrm{H}$ situation. These results tell us that using blockchainbased ACTS can help supply chain add their revenues, moreover, supply chain coordination can help chain members obtain more benefits.

Table 1. Benefits changes with the effective output factor function $\varphi(t)$

\begin{tabular}{ccccccccc}
\hline$\varphi(t)$ & 0.010 & 0.015 & 0.017 & 0.020 & 0.023 & 0.025 & 0.027 & 0.03 \\
\hline$\pi_{r}^{C^{*}}$ & $8 \times 10^{3}$ & $2.1 \times 10^{3}$ & $1.3 \times 10^{3}$ & $0.6 \times 10^{3}$ & $0.26 \times 10^{3}$ & $0.12 \times 10^{3}$ & $0.06 \times 10^{3}$ & $0.09 \times 10^{3}$ \\
$\pi_{m}^{C^{*}}$ & $12 \times 10^{3}$ & $5.3 \times 10^{3}$ & $1.9 \times 10^{3}$ & $0.9 \times 10^{3}$ & $0.4 \times 10^{3}$ & $0.21 \times 10^{3}$ & $0.09 \times 10^{3}$ & $0.03 \times 10^{3}$ \\
$\pi_{r}^{H^{*}}$ & $10 \times 10^{3}$ & $2.7 \times 10^{3}$ & $0.8 \times 10^{3}$ & $0.38 \times 10^{3}$ & $0.16 \times 10^{3}$ & $0.09 \times 10^{3}$ & $0.04 \times 10^{3}$ & $0.02 \times 10^{3}$ \\
$\pi_{m}^{H^{*}}$ & $5 \times 10^{3}$ & $1.6 \times 10^{3}$ & $1.3 \times 10^{3}$ & $0.76 \times 10^{3}$ & $0.3 \times 10^{3}$ & $0.17 \times 10^{3}$ & $0.08 \times 10^{3}$ & $0.03 \times 10^{3}$ \\
$\pi_{r}^{Q^{*}}$ & $2 \times 10^{3}$ & $0.6 \times 10^{3}$ & $0.4 \times 10^{3}$ & $0.2 \times 10^{3}$ & $0.1 \times 10^{3}$ & $0.06 \times 10^{3}$ & $0.036 \times 10^{3}$ & $0.01 \times 10^{3}$ \\
$\pi_{m}^{Q^{*}}$ & $4 \times 10^{3}$ & $1.2 \times 10^{3}$ & $0.8 \times 10^{3}$ & $0.4 \times 10^{3}$ & $0.2 \times 10^{3}$ & $0.1 \times 10^{3}$ & $0.07 \times 10^{3}$ & $0.02 \times 10^{3}$ \\
\hline
\end{tabular}

According to Conclusion 2, we get Figures 7 and 8. In Figure 7, the abscissa represents the revenues difference value of chain members before and after adopting the blockchain-based ACTS, and the ordinate demonstrates the investment costs of chain members about the blockchain-based ACTS. From Figure 7, we can get that with the growth of the investment costs about the blockchainbased ACTS, benefits difference value of chain members before and after adopting blockchainbased ACTS will reduce. Meanwhile, we can get when the investment costs about the blockchainbased ACTS is lower than a certain value $z_{1}$, investing in the blockchain-based ACTS can help chain members gain more benefits, otherwise, members of the supply chain will spend more than they earn.

In Figure 8, the abscissa represents the revenues difference value of chain members before adopting blockchain-based ACTS and after coordination situation, and the ordinate demonstrates the investment costs of chain members about the blockchain-based ACTS. From Figure 8, we can get that with the growth of the investment costs about the blockchain-based ACTS, benefits difference values of chain members before adopting blockchain-based ACTS and after coordination situation will reduce. Meanwhile, we can get when the investment costs about the blockchain-based ACTS is lower than a certain value $\min \left\{z_{2} z_{3}\right\}$ ( in this figure, it is $z_{2}$ ), investing in the 
blockchain-based ACTS can help chain members gain more benefits, otherwise, members of the supply chain will spend more than they earn.

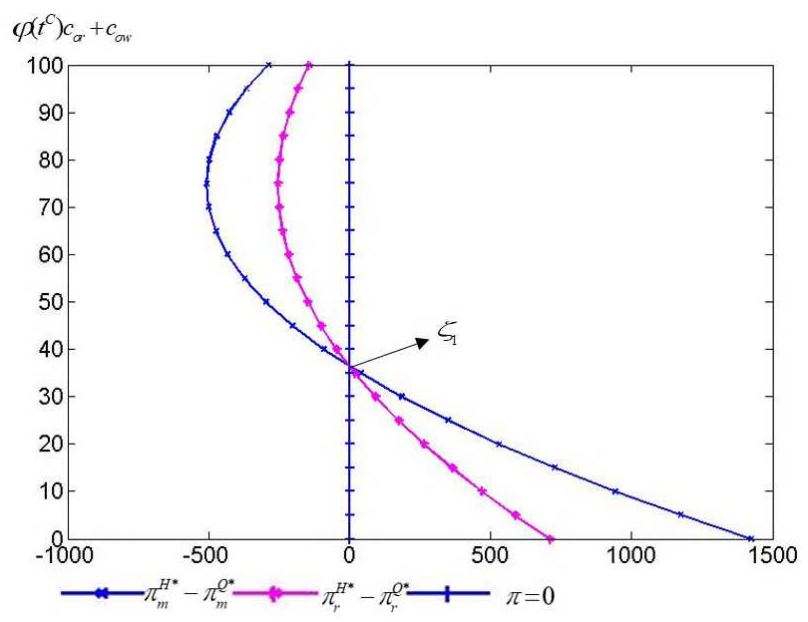

Figure 7. Investment condition of chain members in the $\mathrm{H}$ situation

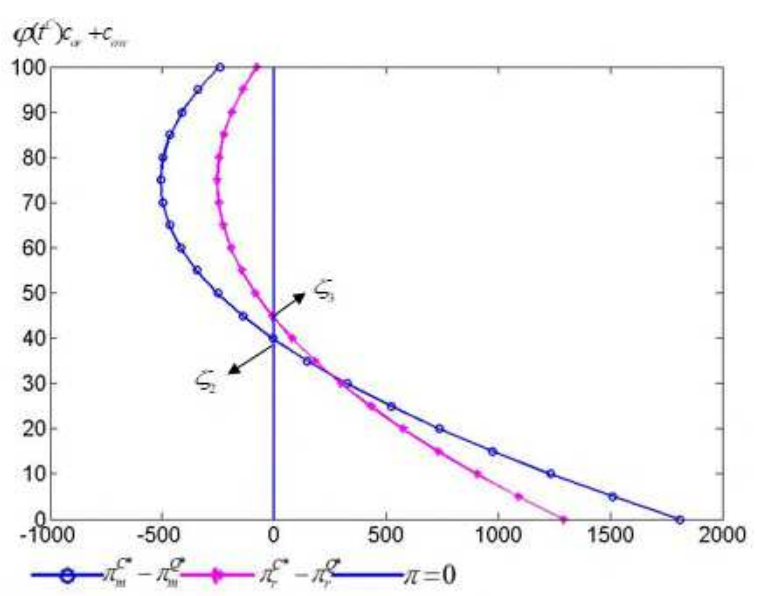

Figure 8. Investment condition of chain members in the $\mathrm{C}$ situation

According to Conclusion 1, we get Figure 9. In Figure 9, the abscissa represents the revenues difference value of chain members before and after coordination, and the ordinate demonstrates the revenue sharing coefficient of the retailer. From Figure 8, we can get that when the revenue sharing coefficient of the retailer is in a certain range $(1 / 2 \leq r \leq 3 / 4)$, adopting the price discount and revenue-sharing contract will achieve the high-quality fresh products supply chain coordinate. Conclusion 1 was confirmed. 


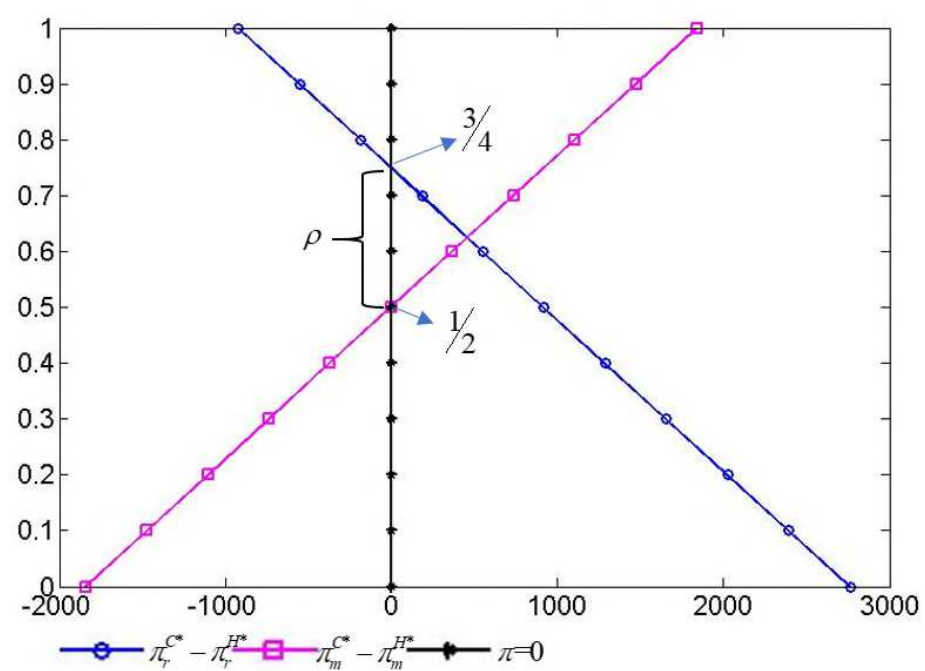

Figure 9 Coordination conditions after adopting blockchain-based ACTS

\section{Conclusions, Significance and future researches}

\subsection{Conclusions}

For consumers, following the consumption level improvement, they have a higher requirement for high-quality fresh products' safety, information transparency and inquiry convenience. However, facing these mixed goods, consumers need a real, reliable and credible mechanism to provide a strong basis for their purchased goods. In addition, for enterprises, How to ensure the accuracy of market feedback data and preventing some sellers from fleeing goods are urgent problems. The account book of the traditional traceability system is stored by the stakeholders in the supply chain. When the account book information is unfavorable to the stakeholders, there is a risk of tampering with the account book. The blockchain-based ACTS can effectively solve these problems.

Therefore, some fresh producer and retailer begin to use the blockchain-based ACTS. Its applications in JD Zhizhen chain and Alibaba ant chain have proved that it can help to improve the repeat purchase rate and the product circulation rate. However, for many fresh producers and retailers, using the blockchain-based ACTS needs the additional expenditure. Therefore, they want to know the investment conditions about the blockchain-based ACTS and how to coordinate the supply chain after adopting the blockchain-based ACTS.

To solve the aforementioned problems, we chosen a fresh supply chain with a producer and a retailer. Then, considering the changes of the repeat purchase rate and the product circulation rate in the new background, we refactored the demand function model. Afterwards, we built four benefits models and proposed a price discount and revenue-sharing contract to coordinate the supply chain after adopting the blockchain-based ACTS. Finally, we get some interesting findings.

1. With the growth of the repurchase rate, benefits of chain members in the proposed three 
situations will increase. Thus, we can know that after using blockchain-based ACTS, if chain members want to gain more benefits, they should try their best to excavate the value of the blockchain-based ACTS and increase the repurchase rate.

2. Following the rise of the effective output factor function, profits of the producer and the retailer in different situations will reduce. These results tell us that using blockchain-based ACTS can help supply chain add their revenues, moreover, supply chain coordination can help chain members obtain more benefits.

3. In the H model, when the investment costs about the blockchain-based ACTS is lower than a certain value $z_{1}$, investing in the blockchain-based ACTS can help chain members gain more benefits. In the coordination situation, when the investment costs about the blockchain-based ACTS is lower than a certain value min $\left.k_{2} z_{3}\right\}$, investing in the blockchain-based ACTS can help chain members gain more benefits.

4. When the revenue sharing coefficient of the retailer is in a certain range $(1 / 2 \leq r \leq 3 / 4)$, adopting the price discount and revenue-sharing contract achieve the high-quality fresh products supply chain coordinate. Meanwhile, the discounts about the wholesale price have a negative relationship with the revenue sharing coefficient.

\subsection{Research significance}

This research has some academic values. 1) Considering the changes of the repeat purchase rate and the product circulation rate in the new background, we refactored the demand function model. This enriched the demand function research in the new environment. 2) We built four benefits models considering the blockchain-based ACTS costs and the changes of the repeat purchase rate and the product circulation rate. Then, we gained the investment condition about the blockchain-based ACTS. This enriched the investment decision theory about fresh supply chain in the new technology environment. 3) We proposed a price discount and revenue-sharing contract to coordinate the supply chain. This enriched the coordination theory of fresh supply chain and expanded the usage situation of the price discount and revenue-sharing contract.

This research has some application values. 1) The proposed demand function can provide a theoretical support for retailers and fresh producers to forecast market demand. 2) The gained investment conditions can help fresh producers and retailers to make a decision when they want to invest in the blockchain-based ACTS. 3) The proposed coordination contract will be a strong support for coordinating the supply chain after adopting the blockchain-based ACTS.

\subsection{Future researches}


This paper considers a simplified two-stage decentralized fresh supply chain model. We mainly analyzed the deterministic demand form related to freshness, price and repeat purchase rate. In the future, the random demand should be considered. In addition, this study only considered the traceability system to reduce the double loss and the repeat purchase rate, and ignored the effects of the brand value increases about high-quality agricultural products on consumers' demand and preferences. Therefore, in the next step, we can study how to improve consumers' demand and preference for the blockchain-based ACTS.

\section{Authors' contributions}

Pan Liu conceived and designed the experiments and performed the experiments, and then analyzed the data and wrote the paper.

\section{Acknowledgment}

The authors would like to thank the following research grants: Key R\&D and Promotion Projects in Henan, China (Soft Science) (No. 212400410307), Key scientific research projects of higher education institutions in Henan, China (No.21A630016), General Project of Humanities and Social Sciences in Henan, China (No. 2020-ZDJH-141), Top Talent Project of Henan Agricultural University (No. 30500681), and Creator Talent Support Plan of Henan Agricultural University (No. 30200757).

\section{Conflict of interest}

The authors declare that there is no conflict interest.

\section{References:}

Aiello, G., Enea, M., \& Muriana, C. (2015). The expected value of the traceability information. European Journal of Operational Research, 244(1), 176-186

Boehm, V. A. J., Kim, J., \& Hong, J. W. K. (2017). Holistic tracking of products on the blockchain using NFC and verified users. Paper presented at the International Workshop on Information Security Applications from Springer, Cham, 184-195.

Bumbudsanpharoke, N., \& Ko, S. (2015). Nano-Food Packaging: An Overview of Market, Migration Research, and Safety Regulations. Journal of Food Science, 80(5), R910-R923

Cai, X., Chen, J., Xiao, Y., \& Xu, X. (2010). Optimization and Coordination of fresh products Supply Chains with Freshness-Keeping Effort. Production and Operations Management, 19(3), 261-278

Cai, X., Jian, C., Xiao, Y., Xu, X., \& Gang, Y. (2013). Fresh-product supply chain management with logistics outsourcing. Omega, 41(4), 752-765

Chen, H., Chen, Z., Lin, F., \& Zhuang, P. (2021). Effective Management for Blockchain-Based AgriFood Supply Chains Using Deep Reinforcement Learning. IEEE Access, PP(99), 1

Costa, C., Antonucci, F., Pallottino, F., Aguzzi, J., Sarriá, D.,... Menesatti, P. (2013). A Review on Agrifood Supply Chain Traceability by Means of RFID Technology. Food and Bioprocess Technology, 
$6(2), 353-366$

Dai, B., Yu, N., Xia, X., \& Lic, J. (2021). Interactions of Traceability and Reliability Optimization in a Competitive Supply Chain with Product Recall. European Journal of Operational Research, 290(1), 116-131

Dai, H., Tseng, M. M., \& Zipkin, P. (2015). Design of Traceability Systems for Product Recall. Social Science Electronic Publishing, 53(2), 511-531

Dai, J. B., Fan, L., Lee, N. K. S., \& Li, J. (2017). Joint optimisation of tracking capability and price in a supply chain with endogenous pricing. International Journal of Production Research, 55(17-18), $1-20$

Digital, J. (2020). 2020 JD Blockchain Technology Practice White Paper. (Reprinted.

Fan, Z. P., Wu, X. Y., \& Cao, B. B. (2020). Considering the traceability awareness of consumers: should the supply chain adopt the blockchain technology? Annals of Operations Research(1), 1-24

Galvin, D. (2017). Ibm and walmart: blockchain for food safety: PowerPoint Presentation. Reprinted.

Hayrutdinov, S., Saeed, M., \& Rajapov, A. (2020). Coordination of Supply Chain under Blockchain System-Based Product Lifecycle Information Sharing Effort. Journal of Advanced Transportation, 2020, 1-10

He, X., Chen, X., \& Li, K. (2019). A Decentralized and Non-reversible Traceability System for Storing Commodity Data. KSII Transactions on Internet \& Information Systems, 13(2), 619-627

Kamble, S. S., Gunasekaran, A., \& Sharma, R. (2019). Modeling the blockchain enabled traceability in agriculture supply chain. International Journal of Information Management, 52

Kamble, S. S., Gunasekaran, A., \& Sharma, R. (2020). Modeling the blockchain enabled traceability in agriculture supply chain. International Journal of Information Management, 52

Khler, S., \& Pizzol, M. (2020). Technology assessment of blockchain-based technologies in the food supply chain. Journal of Cleaner Production, 269, 122193

Kristoffer, F., \& David, S. (2018). The Supply Chain Has No Clothes: Technology Adoption of Blockchain for Supply Chain Transparency. Logistics, 2(1), 2

LIU, P. (2020). Investment decision and coordination of green agri-food supply chain considering information service based on blockchain and Big Data. Journal of Cleaner Production, 2020, 1-20

Madichie, N. O., \& Yamoah, F. A. (2017). Revisiting the European Horsemeat Scandal: The Role of Power Asymmetry in the Food Supply Chain Crisis. Thunderbird International Business Review, 59(6), 663-675

Nakamoto, S. (2008, 2019-11-28). Bitcoin: a Peer-to-peer Electronic Cash System, from https://bitcoin.org/bitcoin.pdf

News, S. (2019, 2021-04-12), from https://news.sap.com/2019/03/bumble-bee-foods-sap-createblockchain-track-fish/

Papa, S. F. (2017). Use of Blockchain Technology in Agribusiness: Transparency and Monitoring in Agricultural Trade. Paper presented at the 2017 International Conference on Management Science and Management Innovation (MSMI 2017).

Pedersen, A. B., Risius, M., \& Beck, R. (2019). A Ten-Step Decision Path to Determine When to Use Blockchain Technologies. MIS Quarterly Executive, 18(2), 99-115

Piramuthu, S., Farahani, P., \& Grunow, M. (2013). RFID-generated traceability for contaminated product recall in perishable food supply networks. European Journal of Operational Research, 225(2), 253262

Pouliot, S. (2008). Traceability and food safety: Liability, reputation, and willingness to pay. 


\section{Dissertations \& Theses - Gradworks}

Rejeb, A. (2018). Halal meat supply chain traceability based on HACCP, Blockchain and internet of things. Acta Technica Jaurinensis, 11(4), 218-247

S. Kamble, A. G. H. A. (2019). Understanding the blockchain technology adoption in supply chainsindian context. Int. J. Prod. Res, 57, 2009-2033

Saak, \& Alexander, E. (2013). Traceability and reputation in supply chains. International Journal of Production Economics, 77, 149-162

Salah, K., Nizamuddin, N., Jayaraman, R., \& Omar, M. (2019). Blockchain-based Soybean Traceability in Agricultural Supply Chain. IEEE Access, $\mathrm{PP}(99)$

Sambrekar, K. (2019). Fast and Efficient Multiview Access Control Mechanism for Cloud Based Agriculture Storage Management System. International journal of cloud applications and computing, 9(1), 33-49

Sohu. (2018, 2021-04-12). Maersk, the world's largest shipping company, has successfully used blockchain to track shipments, from https://www.sohu.com/a/127970964_475384

Ss, A., \& Kd, B. (2020). Blockchain technology adoption, architecture, and sustainable agri-food supply chains. Journal of Cleaner Production, 284, 124731

Ssk, A., Ag, B., Vk, C., Ab, D., \& Cf, E. (2020). A machine learning based approach for predicting blockchain adoption in supply Chain. Technological Forecasting and Social Change, 163: 120465.

Sunny, J., Undralla, N., \& Pillai, V. M. (2020). Supply chain transparency through blockchain-based traceability: An overview with demonstration. Computers \& Industrial Engineering, 150

Sy, A., \& Kz, B. (2020). Combating product label misconduct: The role of traceability and market inspection. European Journal of Operational Research, 282(2), 559-568

Taste, S. L. (2020). The world's first blockchain farm-rice bags for good food, 2020/05/16, from http://www.agrichains.cn/

Tayal, A., Solanki, A., Kondal, R., Nayyar, A., \& Kumar, N. (2020). Blockchain-based Efficient Communication for Food Supply Chain Industry: Transparency and Traceability Analysis for Sustainable Business. International Journal of Communication Systems, 34(4): e4696

Tian, F. (2016). An agri-food supply chain traceability system for China based on RFID \& blockchain technology. Paper presented at the 2016 13th international conference on service systems and service management (ICSSSM). IEEEfrom

Tsang, Y. P., Choy, K. L., \& Wu, C. H. E. A. (2019). Blockchain-Driven IoT for Food Traceability With an Integrated Consensus Mechanism. IEEE Access, 7, 129000-129017

Wen-Li, L. I., \& Zhao, S. (2019). Research on Decision-making Model of High-quality fresh products Dual-channel Supply Chain considering the Application of Traceability System. Operations Research and Management Science,28(6),99-101.

Wu, X. Y., Fan, Z. P., \& Cao, B. B. (2021). An analysis of strategies for adopting blockchain technology in the high-quality fresh products supply chain. International Journal of Production Research, (5), $1-18$

Zhao, G., Liu, S., \& Lopez, C. E. A. (2019). Blockchain technology in agri-food value chain management: A synthesis of applications, challenges and future research directions. Computers in Industry, 109, 83-99 